\title{
AN AMPHIBIAN MODEL TO TEST THE EFFECTS OF XENOBIOTIC CHEMICALS ON DEVELOPMENT OF THE HEMATOPOIETIC SYSTEM
}

\author{
Louise A. Rollins-Smith, $*+$ B. Diane Hopkins, $\neq$ and Laura K. Reinert $\dagger$ \\ $\dagger$ Departments of Microbiology and Immunology and of Pediatrics, Vanderbilt University Medical Center, Nashville, Tennessee 37232, USA \\ \$Department of Biology, Palm Beach Atlantic University, West Palm Beach, Florida 33416, USA
}

(Received 29 September 2003; Accepted 30 April 2004)

\begin{abstract}
A number of manmade chemicals have deleterious effects on the developing immune system. Very few assay systems are available to study the effects of xenobiotics on hematopoietic stem cells. In rodent models, assays require exposure of pregnant females and analysis of the hematopoietic potential of stem cells from the offspring. These models are less relevant to lower vertebrates such as fish or amphibians where exposure of embryos is direct. To overcome this problem, an amphibian model was developed. Diploid (2N) embryos (16-20 h of age) of the South African clawed frog, Xenopus laevis, were exposed to $10 \mu \mathrm{g} / \mathrm{ml}$ diazinon or $10^{-6} \mathrm{M}$ lead acetate for $2 \mathrm{~h}$. After $2 \mathrm{~h}$, the ventral blood island (VBI) was transplanted from a chemically treated or untreated control embryo to an untreated triploid $(3 \mathrm{~N})$ host embryo. After $55 \mathrm{~d}$, the contribution of the donor VBI-derived stem cells to populations in the blood, thymus, and spleen was assessed by flow cytometry. Diazinon, but not lead acetate, interfered with the ability of transplanted stem cells to contribute to hematopoiesis. Because amphibian embryos are very sensitive indicators of the toxic effects of chemicals, this VBI assay could be employed to test any toxic chemical that is suspected of having a negative effect on development of the hematopoietic system.
\end{abstract}

Keywords-Amphibian immunity Immunotoxic Hematopoietic stem cell Diazinon Lead

\section{INTRODUCTION}

The amphibian immune system is very similar to that of mammalian species (reviewed in $[1,2]$ ). The adaptive immune system is characterized by organs and cells that serve similar functions as those of mammals. Amphibians have $\mathrm{T}$ and $\mathrm{B}$ lymphocytes [3] that express rearranging T-cell receptors and immunoglobulin receptors [4-6]. They have a major histocompatibility complex encoding classical class I and class II molecules (reviewed in [7]). Amphibians express several immunoglobulin isotypes [8-12], and they can produce leukocyte-derived cytokines [13-17]. Their innate immune system includes phagocytic cells, a complement system, and natural killer cells (reviewed in [2]).

The immune system, as it has evolved in all vertebrate species including amphibians, protects the host from infection by environmental pathogens. The great diversity and flexibility of the adaptive immune response depends on a continuing process of self-renewal from a population of hematopoietic stem cells. Although immunotoxic effects of xenobiotic chemicals on the mature immune system are well-documented in mammalian species (reviewed in $[18,19]$ ), there is much less information available on the effects of these chemicals on the immature or developing immune system (reviewed in [2022]). Some studies suggest that toxic agents delivered to pregnant females or newborn animals have more pronounced effects than if they are delivered to adult animals (reviewed in $[21,22])$. These studies suggest that the developing immune system may be especially vulnerable to the toxic effects of xenobiotics. Most insults to the adult immune system cause temporary loss of function because many components of the immune system will renew themselves. If, however, pluripo-

* To whom correspondence may be addressed (louise.rollins-smith@vanderbilt.edu). tential hematopoietic stem cells are destroyed (for example by gamma irradiation), the consequence is irreversible loss of renewal capability. Most immunotoxicology studies use rodent (mouse and rat) model systems (reviewed in [20-22]). They are viewed as very good models of the human immune system, and they are the ideal choice for most studies. However, studies of the effects of toxic agents on the very early immune system must deal with the problem that mammalian species develop in utero. Manipulations of the developing fetus are difficult, and determinations of fetal exposure are necessarily indirect. These models are less relevant to lower vertebrates such as fish or amphibians where exposure of embryos to hazardous chemicals is direct. Because amphibians develop free of maternal influences, they may be valuable models to study potentially adverse effects of environmental chemicals during early development.

Amphibians long have been the favorite choice for studies of embryonic development, and thus the location of embryonic stem cell compartments and the pattern of development of the hematopoietic system are very well understood (reviewed in [23]). Two regions of the lateral plate mesoderm contribute to hematopoiesis [24-27]. The dorsal lateral plate and the ventral blood island (VBI) both give rise to erythrocytes, thymocytes, T lymphocytes, and B lymphocytes [25,26,28,29]. Ventral blood island is the main stem cell source for larval hematopoiesis (primitive stem cell source) and the dorsal lateral plate contributes cells that function later in the postmetamorphic period (definitive stem cell source; reviewed in [23]). For these studies, we chose to transplant the VBI of exposed and control embryos and examine larval populations of lymphocytes and erythrocytes about $50 \mathrm{~d}$ later when the tadpole lymphocyte population is maximal prior to metamorphic transition [29,30].

Our results demonstrate that the common pesticide diazinon, but not lead acetate, interfered with development of he- 


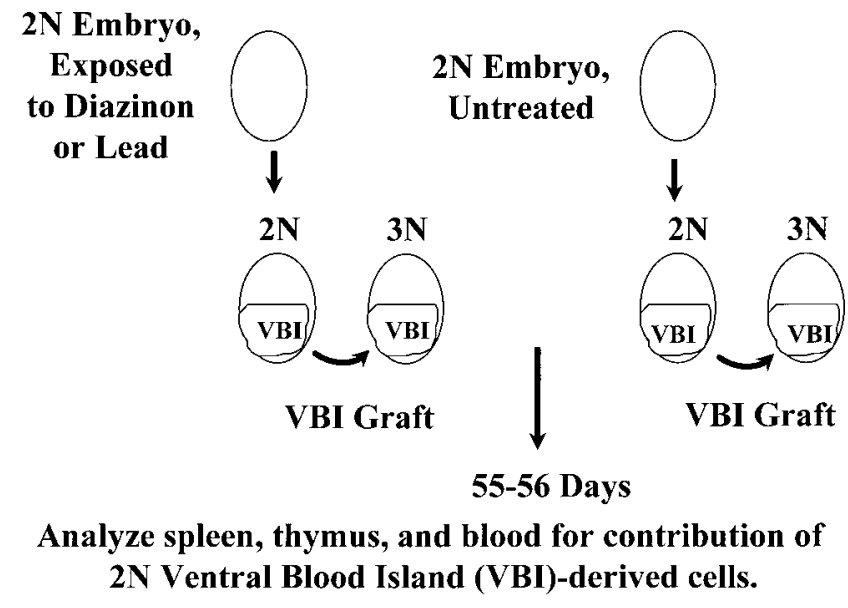

Fig. 1. Experimental design. Diploid (2N) embryos at 14 to $18 \mathrm{~h}$ of age were treated with $10 \mu \mathrm{g} / \mathrm{ml}$ of diazinon or $10^{-6} \mathrm{M}$ lead acetate or were left untreated in full-strength Holtfreter's solution for $2 \mathrm{~h}$. The ventral blood island (VBI) from experimental or control embryos was removed surgically and transplanted to an age-matched triploid $(3 \mathrm{~N})$ embryo. At 55 to $56 \mathrm{~d}$ postimplantation, hosts were sacrificed and the contribution of VBI-derived $2 \mathrm{~N}$ hematopoietic stem cells was determined.

matopoietic cells. These experiments demonstrate the feasibility of this direct assay system as an alternative to current mouse or rat models for testing the effects of immunotoxic chemicals on the developing immune system.

\section{MATERIALS AND METHODS}

\section{Experimental design}

The overall design of the experiments is shown in Figure 1. Briefly, diploid $(2 \mathrm{~N})$ embryos were exposed to potentially immunotoxic chemicals for $2 \mathrm{~h}$. Control embryos were untreated. The VBI from an experimental or control embryo was removed surgically and transplanted to an age-matched triploid (3N) embryo. Transplanted embryos developed into tadpoles and were sacrificed 55 to 56 d later. Cells from the blood, thymus, and spleen were removed, and the nuclei were stained to determine the contribution of transplanted $2 \mathrm{~N}$ hematopoietic stem cells by flow cytometry.

\section{Frogs}

Although Xenopus laevis developed from an ancient tetraploid species [31] and has almost twice the number of chromosomes as the natural diploid species, Xenopus tropicalis, the mitotic karyotype is 18 chromosome pairs [32]. Xenopus laevis, therefore, is regarded as a functional diploid, and we have followed the accepted convention of referring to the natural chromosome complement as diploid or $2 \mathrm{~N}$ and the $2+$ 1 chromosome complement as triploid or $3 \mathrm{~N}$.

Major histocompatibility complex homozygous J-strain females were induced to ovulate by injection of human chorionic gonadotropin according to standard protocols [29]. J-strain males were sacrificed to provide sperm for in vitro fertilization [29]. Transplanted tadpoles were reared at a density of approximately $10 / 4 \mathrm{~L}$ of dechlorinated tap water. Their water was changed three times weekly, and they were fed finely crushed nettle leaf. Larval stages were determined according to the Normal Table of Nieuwkoop and Faber [33]. Animal manipulations were performed in accordance with the Vanderbilt University Institutional Animal Care and Use Committee (Nashville, TN, USA).

\section{Production of triploid (3N) frogs}

Triploid embryos were produced by the method of Kawahara [34]. In vitro fertilized eggs were immersed in cold $\left(2-3^{\circ} \mathrm{C}\right) 5 \%$ De Boer's solution [35] for $15 \mathrm{~min}$ at $15 \mathrm{~min}$ postfertilization. Cold 5\% De Boer's solution was then replaced by room temperature dechlorinated tap water.

\section{Embryonic exposure to xenobiotic chemicals}

Diploid (2N) and triploid (3N) embryos were placed in sterile dechlorinated tap water or modified Holtfreter's solution [29] with antibiotics (100 International Units/ml penicillin and $100 \mu \mathrm{g} / \mathrm{ml}$ streptomycin) and incubated at $18^{\circ} \mathrm{C}$ for 16 to 20 h until they reached Nieuwkoop and Faber stages 15 to 23 [33]. The jelly coat and fertilization membrane were removed manually with fine watchmaker's forceps. After removal of the jelly coat and fertilization membrane, the embryos were placed in Holtfreter's solution with antibiotics. Two hours prior to the time of transplantation, some $2 \mathrm{~N}$ embryos were placed in modified Holtfreter's solution containing $10 \mu \mathrm{g} / \mathrm{ml}$ diazinon (diluted from a commercially available $25 \%$ diazinon concentrate containing $75 \%$ inert ingredients $)$ or $10^{-6} \mathrm{M}(3.8 \mu \mathrm{g} / \mathrm{ml})$ lead acetate (Sigma, St. Louis, MO, USA) for 2 h. A 2-h exposure was chosen because of the very rapid rate of development of $X$. laevis embryos. After exposure, the embryos were returned to fresh modified Holtfreter's solution and placed at $4^{\circ} \mathrm{C}$ until they were used as transplant donors. Untreated control embryos remained in Holtfreter's solution with antibiotics for 2 $\mathrm{h}$ and were placed at $4^{\circ} \mathrm{C}$ until they were used as transplant donors.

\section{Ventral blood island transplantation}

The VBI region was transplanted as described previously [29]. A $2 \mathrm{~N}$ and $3 \mathrm{~N}$ pair of embryos at the same stage was placed ventral side up in agar-lined depressions. An area of ventral ectoderm and underlying mesoderm containing the VBI was removed from the $2 \mathrm{~N}$ embryo with finely drawn glass needles. An identical area of ventral ectoderm and mesoderm was then removed from the $3 \mathrm{~N}$ embryo and discarded. The $2 \mathrm{~N}$ VBI was placed on the $3 \mathrm{~N}$ embryo and held in place with a piece of sterile broken cover slip. Grafts were allowed to heal for 30 to $60 \mathrm{~min}$ at room temperature, and the cover slip was removed. Transplanted embryos remained in full strength Holtfreter's solution with antibiotics for 2 to $4 \mathrm{~h}$ and were then transferred to $10 \%$ Holtfreter's solution containing antibiotics.

\section{Preparation of cells and analysis by flow cytometry}

At 55 to $56 \mathrm{~d}$ post-transplantation, $3 \mathrm{~N}$ host tadpoles were sacrificed and cells from blood, thymus, and spleen were collected as described previously [29]. For counting, cells from individual organs or blood were washed once and resuspended in $600 \mu \mathrm{l}$ of L-15 medium supplemented with $1 \%$ fetal bovine serum, 100 International Unit/ml penicillin, and $100 \mu \mathrm{g} / \mathrm{ml}$ of streptomycin [29]. An aliquot was removed, stained with trypan blue, and viable cells were counted with a hemocytometer counting chamber. Remaining cells were stained with propidium iodide as described previously [29] and analyzed on a Becton-Dickinson FACScan flow cytometer (Franklin Lakes, NJ, USA). Sample analysis employed gated data collection in which linear fluorescence area and linear fluorescence width signals were used to set data acquisition gates excluding cell aggregates and debris. The integrated linear fluorescence signals, collected on a single cell population, were accumulated in 1,024 channel histograms, and list mode data files were 


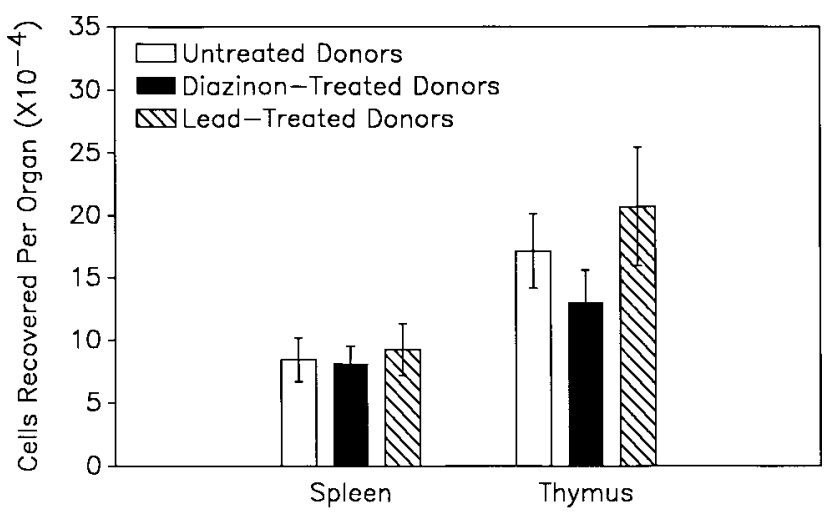

Fig. 2. Total cells (mean \pm standard error) recovered from the spleen and thymus of individual ventral blood island-transplanted tadpoles sacrificed at 55 to $56 \mathrm{~d}$ postimplantation. Tadpoles receiving implants from untreated donors $(n=9)$ were at Nieuwkoop and Faber stages 50 to 61 ; tadpoles receiving implants from diazinon-treated donors $(n=6)$ were at stages 51 to 58 ; and tadpoles receiving implants from lead-treated donors $(n=5)$ were at stages 53 to 59. Data were compared by a Student's $t$ test. Total cells recovered from spleen and thymus of hosts of diazinon-treated or lead-treated donors were not significantly different from total cells recovered from hosts of untreated donors.

saved for later analysis. The high voltage and gain were adjusted to place the $G_{0} / G_{1}$ peak for a control diploid population at channel 200. The $\mathrm{G}_{0} / \mathrm{G}_{1}$ peak for triploid cells thus would fall at about channel 300 . The percentage of $2 \mathrm{~N}$ and $3 \mathrm{~N}$ cells present in each chimeric cell population were determined after analysis of 5,000 to 10,000 nuclei per sample using ModFit analysis software (Verity Software House, Topsham, ME, USA).

\section{Statistical comparison of data}

Differences in the total number of cells (mean \pm standard error $[\mathrm{SE}]$ ) recovered from the spleen and thymus of individual VBI-transplanted tadpoles (Fig. 2); differences in the percentage of $2 \mathrm{~N}$ VBI-derived cells (mean $\pm \mathrm{SE}$ ) in spleen, thymus, and blood of the tadpoles receiving implants from untreated donors, diazinon-treated $(10 \mu \mathrm{g} / \mathrm{ml})$ donors, or lead acetate treated donors $\left(10^{-6} \mathrm{M}\right)$ donors (Figs. 3 and 4$)$ were compared by Student's $t$ test. Differences in percent survival

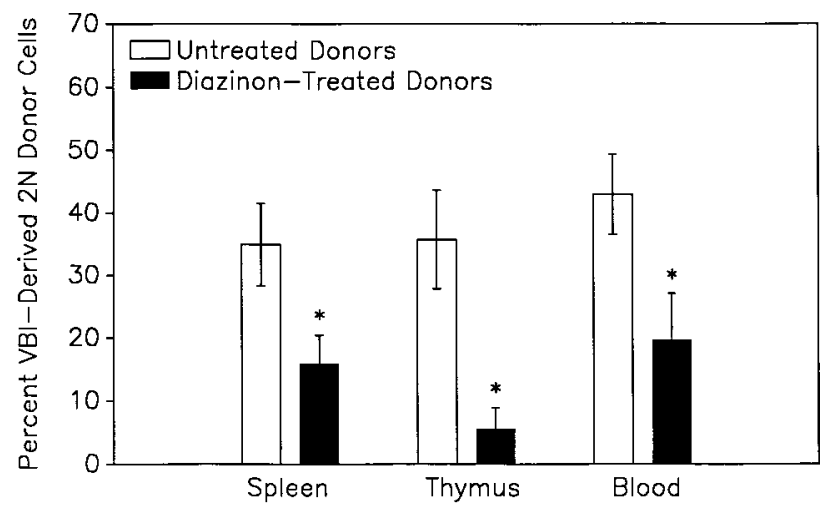

Fig. 3. Percentage of $2 \mathrm{~N}$ ventral blood island (VBI)-derived cells (mean \pm standard error) in spleen, thymus, and blood of the tadpoles receiving implants from untreated donors $(n=20$ including 11 historical controls) [29] or diazinon-treated $(10 \mu \mathrm{g} / \mathrm{ml})$ donors $(n=6)$. $*$ Significantly less than recipients of implants from untreated donors by Student's $t$ test, $p \leq 0.05$.

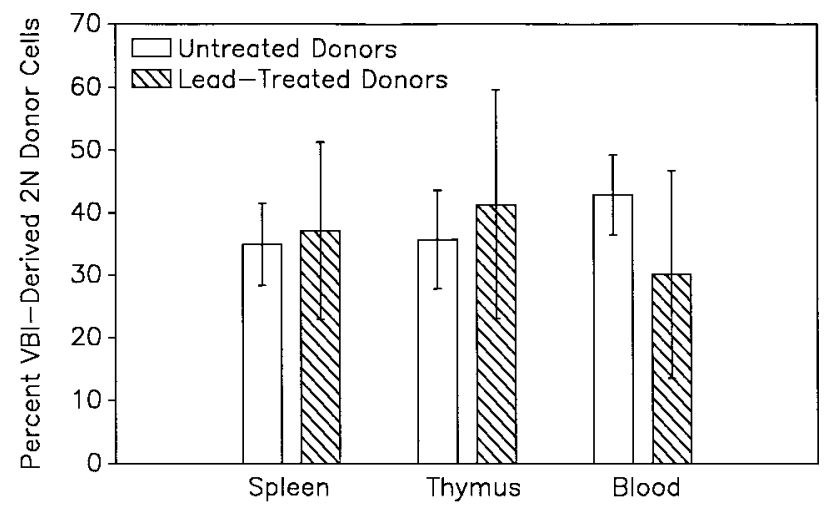

Fig. 4. Percentage of $2 \mathrm{~N}$ ventral blood island (VBI)-derived cells (mean \pm standard error) in spleen, thymus, and blood of the tadpoles receiving implants from untreated donors $(n=20$ including 11 historical controls) [29] or lead-treated $\left(10^{-6} \mathrm{M}\right)$ donors $(n=5)$. Data were compared by a Student's $t$ test. The percentage of $2 \mathrm{~N}$ VBIderived cells in spleen, thymus, and blood of tadpoles receiving implants from lead-treated donors was not significantly different from that of tadpoles receiving implants from untreated donors.

of control, diazinon-treated, or lead-treated groups of $2 \mathrm{~N}$ embryos (Table 1) were compared by a Chi-Square test.

\section{RESULTS}

Assessment of the suitability of the host environment for development of hematopoietic cells

Previous studies have demonstrated that embryonic stem cells resident in the VBI contribute about $35 \%$ of total cells (predominantly lymphocytes) recovered from the spleen and thymus in late larval life $[26,28,29]$. To determine whether $3 \mathrm{~N}$ hosts receiving implants from diazinon-treated or lead-treated embryos would provide a suitable environment for development of $2 \mathrm{~N}$-donor derived cells, the total number of leukocytes recovered from the spleen and thymus of hosts receiving grafts from chemically treated embryos was compared with that recovered from hosts receiving grafts from untreated embryos. The total number of cells recovered per organ from hosts receiving implants from chemically treated embryos was not significantly different from those receiving control implants (Student's $t$ test, $p \leq 0.05$, Fig. 2). This demonstrates that the method of VBI transplantation did not interfere with the normal development of the thymus and spleen and that $3 \mathrm{~N}$ hosts provided a suitable environment for maturation of the implanted stem cells regardless of the source.

Table 1. Effects of diazinon and lead on embryo survival at three weeks after exposure

\begin{tabular}{lccl}
\hline Treatment & No. treated & \% survival & $\begin{array}{c}\text { Statistical } \\
\text { comparison }^{\text {a }}\end{array}$ \\
\hline Holtfreter's control & 93 & 75.3 & \\
$1 \mu \mathrm{g} / \mathrm{ml}$ Diazinon & 10 & 80.0 & Not significant \\
$10 \mu \mathrm{g} / \mathrm{ml}$ Diazinon & 46 & 60.9 & Not significant \\
$100 \mu \mathrm{g} / \mathrm{ml}$ Diazinon & 26 & 73.1 & Not significant \\
$10^{-7} \mathrm{M}$ Lead acetate & 26 & 61.5 & Not significant \\
$10^{-6} \mathrm{M}$ Lead acetate & 23 & 52.2 & $p \leq 0.05$ \\
$10^{-5}$ M Lead acetate & 26 & 84.6 & Not significant \\
\hline
\end{tabular}

a Percent survival for each experimental group was compared to that of controls exposed to Holtfreter's solution by a Chi Square test. Only a $p$ value $\leq 0.05$ was considered significant. 


\section{Assessment of embryo toxicity following diazinon or lead} treatments

To determine whether a 2-h exposure to diazinon at 1,10 , or $100 \mu \mathrm{g} / \mathrm{ml}$ or exposure to lead acetate at $10^{-7} \mathrm{M}, 10^{-6} \mathrm{M}$, or $10^{-5} \mathrm{M}$ was directly toxic to embryos, the survival of small groups of treated embryos at three weeks of age was compared with that of embryos exposed to Holtfreter's solution. Survival was approximately 60 to $80 \%$ in all experimental groups and did not differ significantly from that of the control group (Table 1, Chi Square test). The single exception was treatment with $10^{-6} \mathrm{M}$ lead acetate; survival was $52.2 \%$. Although survival in the $10^{-6} \mathrm{M}$ lead acetate-treated group was significantly different from that of control embryos ( $p \leq 0.05$ ), survival of embryos treated with $10^{-5} \mathrm{M}$ lead acetate was not different from controls.

\section{Effects of diazinon on hematopoietic stem cells in the VBI}

The percentage of $2 \mathrm{~N}-\mathrm{VBI}-$ derived cells (predominantly leukocytes) that developed in the spleen of nine tadpoles that had received implants from untreated embryos was $33.2 \pm$ 9.2. The percentage of $2 \mathrm{~N}-\mathrm{VBI}$-derived lymphocytes in the thymus of the same tadpoles was $35.9 \pm 11.8$, and the percentage of $2 \mathrm{~N}-\mathrm{VBI}$-derived cells (predominantly erythrocytes) in blood was $32.3 \pm 8.3$. These numbers are very similar to the percentages observed in a previous study of 11 VBI-transplanted tadpoles [29]. In contrast, the percentage of VBI-derived leukocytes in the spleen of six recipients of diazinontreated donors was $15.9 \pm 4.5$, the percentage of VBI-derived thymocytes was $5.6 \pm 3.3$, and the percentage in VBI-derived erythrocytes was $19.7 \pm 7.4$. These percentages are significantly less than controls (Student's $t$ test, $p \leq 0.05$; Fig. 3).

\section{Effects of lead on hematopoietic stem cells in the VBI}

The percentage of VBI-derived leukocytes in the spleen of five recipients of lead-treated donors was $37.1 \pm 14.2$. The percentage of VBI-derived thymocytes in the same tadpoles was $41.3 \pm 18.3$, and the percentage in VBI-derived erythrocytes was $30.1 \pm 16.6$. These percentages were not significantly different from the percentages of VBI-derived cells in recipients of VBI implants from untreated donors (Student's $t$ test, $p \geq 0.05$; Fig. 4).

\section{DISCUSSION}

These studies were undertaken in order to develop a method to assess the potential immunotoxic effects of environmental chemicals on the developing immune system of directly exposed animals such as amphibians or fish. Diazinon was chosen because it is used widely as an agricultural chemical and in household applications to control insects, ticks, and fleas [36]. It has been shown to be immunotoxic for adult mice [37] and the offspring of mice exposed during pregnancy [38]. It is relevant to developing amphibians and fish because of its presence in water systems near agricultural or urban areas [36]. Neither diazinon nor lead were directly toxic to embryos at the concentrations tested (Table 1), and recipient tadpoles developed a normal number of mature lymphocytes in spleen and thymus (Fig. 2). However, consistent with its effects on the mature immune system, treatment of developing embryos with diazinon and transplantation of the VBI resulted in a lower than expected contribution of hematopoietic stem cells from treated embryos (Fig. 3). This suggests that $2 \mathrm{~N}$ hematopoietic stem cells from diazinon-treated embryos were less able to compete with the $3 \mathrm{~N}$ hematopoietic stem cells of the host. However, because the diazinon preparation that we used contained unspecified inert ingredients, we cannot rule out the possibility that the effects on hematopoiesis were due to other materials in the preparation.

Previous studies have shown that chronic or acute exposure of developing rats and chickens to lead acetate results in decreased cell-mediated immune functions [39-41]. However, the acute exposure to lead at the concentration tested in this study $\left(10^{-6} \mathrm{M}=3.8 \mu \mathrm{g} / \mathrm{ml}\right)$ did not appear to interfere with the ability of amphibian hematopoietic stem cells to contribute to the development of the tadpole immune system (Fig. 4). Because exposure of developing embryos in the mammalian models was through the drinking water of their mothers during gestation, it is difficult to compare the exposure levels. The closest study to ours involved injection of avian embryos with 5 or $10 \mu \mathrm{g}$ of lead acetate in a volume of $0.1 \mathrm{ml}$. This exposure would be equivalent to $50 \mu \mathrm{g} / \mathrm{ml}$ or $100 \mu \mathrm{g} / \mathrm{ml}$, about 10 -fold higher than the exposure used in our experiments [40]. A greater effect on amphibian hematopoiesis might have been observed with exposure at a higher concentration. Studies of developing rats suggest that the effects of lead are more pronounced when the exposure occurs at 15 to $21 \mathrm{~d}$ of gestation after the earliest stem cells have colonized the thymus and bone marrow [41]. In our experiment, the exposure to lead occurred in a very narrow window of development and was at a much earlier stage of development. It may have been too early or for too short a duration to have long-term effects.

The value of this model to test the effects of potential immunotoxic chemicals on the developing immune system lies in its simplicity. Amphibian embryos were exposed directly as they would be in a natural setting. In our experiments, the jelly coats and fertilization membrane were removed prior to exposure. However, a recent study of the uptake and metabolism of the herbicide isoproturon by amphibian embryos demonstrated that the jelly coat is not a significant barrier to penetration and metabolism of this agent [42]. With this model system, the effects of a specific chemical agent can be tested independently of any effects it may have on other developing organ systems because only the hematopoietic region of the embryos is transplanted. Production of triploid amphibians is very simple, and the amphibian diploid/triploid transplantation model has been validated repeatedly [23-29]. The principal limitation of this method is the requirement for an individual experienced in the manipulation of amphibian embryos. The VBI-transplantations require patience and skill. The very rapid rate of development of $X$. laevis embryos limits the number of embryos that can be transplanted at embryonic stages 15 to 23. The problem can be overcome, in part, by repeated ovulations and in vitro fertilizations so that small groups of developing embryos can be manipulated over a longer period of time.

This novel method may be a useful alternative to methods used currently to assess the effects of immunotoxic chemicals on the developing immune system. It could be used to test the effects of specific agricultural chemicals that may enter natural aquatic systems and have the potential to alter immune system development in amphibian or fish species. Because the fundamental features of immune system development are the same in all vertebrate species, this model also may have the potential for assessment of the developmental immunotoxicity of agents that could affect mammalian species and human beings. 
Acknowledgement-This research was supported by Grants MCB9421349 and IBN-0131184 from the National Science Foundation. We thank J. Price and the Veteran's Administration Medical Center of Nashville for assistance with flow cytometry.

\section{REFERENCES}

1. Carey C, Cohen N, Rollins-Smith L. 1999. Amphibian declines: An immunological perspective. Dev Comp Immunol 23:459-472.

2. Rollins-Smith LA. 2001. Neuroendocrine-immune system interactions in amphibians. Immunol Res 23:273-280.

3. Bleicher PA, Cohen N. 1981. Monoclonal anti-IgM can separate T-cell from B-cell proliferative responses in the frog Xenopus laevis. J Immunol 127:1549-1555.

4. Schwager J, Grossberger D, Du Pasquier L. 1988. Organization and rearrangement of immunoglobulin $\mathbf{M}$ genes in the amphibian Xenopus. EMBO (Eur Mol Biol Organ) J 7:2409-2415.

5. Du Pasquier L, Schwager J, Flajnik MF. 1989. The immune system of Xenopus. Annu Rev Immunol 7:251-275.

6. Fellah JS, Kerfourn F, Guillet F, Charlemagne J. 1993. Conserved structure of amphibian T-cell antigen receptor beta chain. Proc Natl Acad Sci USA 90:6811-6814.

7. Flajnik MF, Du Pasquier L. 1990. The major histocompatibility complex of frogs. Immunol Rev 150:47-63.

8. Green C, Steiner LA. 1976. Isolation and preliminary characterization of two varieties of low molecular weight immunoglobulin in the bullfrog, Rana catesbeiana. J Immunol 117:364-374.

9. Warr GW, Ruben LN, Edwards GJ. 1982. Evidence for low molecular weight antibodies in the serum of a urodele amphibian, Ambystoma mexicanum. Immunol Lett 4:99-102.

10. Hsu E, Du Pasquier L. 1984. Studies on Xenopus immunoglobulins using monoclonal antibodies. Mol Immunol 21:257-270.

11. Hsu E, Flajnik JF, Du Pasquier L. 1985. A third immunoglobulin class in amphibians. J Immunol 135:1998-2004.

12. Fellah JS, Charlemagne J. 1988. Characterization of an IgY-like low molecular weight immunoglobulin class in the Mexican axolotl. Mol Immunol 25:1377-1386.

13. Watkins D, Cohen N. 1987. Mitogen-activated Xenopus laevis lymphocytes produce a T-cell growth factor. Immunology 62:119125 .

14. Watkins D, Parson SC, Cohen N. 1987. A factor with interleukin1 -like activity is produced by peritoneal cells from the frog, Xenopus laevis. Immunology 62:669-673.

15. Haynes L, Cohen N. 1993. Further characterization of an interleukin-2-like cytokine produced by Xenopus laevis T lymphocytes. Dev Immunol 23:1-23.

16. Koniski A, Cohen N. 1994. Mitogen-activated axolotl (Ambystoma mexicanum) splenocytes produce a cytokine that promotes growth of homologous lymphoblasts. Dev Comp Immunol 18: 239-250.

17. Zou J, Bird S, Minter R, Horton J, Cunningham C, Secombes CJ. 2000. Molecular cloning of the gene for interleukin-1 $\beta$ from Xenopus laevis and analysis of expression in vivo and in vitro. Immunogenetics 51:332-338.

18. Krzystyniak K, Tryphonas H, Fournier M. 1995. Approaches to the evaluation of chemical-induced immunotoxicity. Environ Health Perspect 103:17-22.

19. Van Loveren H, Ross PS, Osterhaus AD, Vos JG. 2000. Contaminant-induced immunosuppression and mass mortalities among harbor seals. Toxicol Lett 112-113:319-324.

20. Holsapple MP. 2003. Developmental immunotoxicity testing: A review. Toxicology 185:193-203.

21. Holladay SD, Blaylock BL. 2002. The mouse as a model for developmental immunotoxicology. Hum Exp Toxicol 21:525531.

22. Smialowicz RJ. 2002. The rat as a model in developmental immunotoxicology. Hum Exp Toxicol 21:513-519.
23. Turpen JB. 1998. Induction and early development of the hematopoietic and immune systems in Xenopus. Dev Comp Immunol 22:265-278.

24. Turpen JB, Knudson CM. 1982. Ontogeny of hematopoietic cells in Rana pipiens: Precursor cell migration during embryogenesis. Dev Biol 89:138-151.

25. Kau C-L, Turpen JB. 1983. Dual contribution of embryonic ventral blood island and dorsal lateral plate mesoderm during ontogeny of hemopoietic cells in Xenopus laevis. J Immunol 131: 2262-2266.

26. Maéno M, Todate A, Katagiri C. 1985. The localization of precursor cells for larval and adult hemopoietic cells in Xenopus laevis in two regions of embryos. Dev Growth Differ 27:137148.

27. Maéno M, Tochinai S, Katagiri C. 1985. Differential participation of ventral and dorsolateral mesoderms in the hemopoiesis of Xenopus, as revealed in diploid-triploid or interspecific chimeras. Dev Biol 110:503-508.

28. Smith PB, Flajnik MF, Turpen JB. 1989. Experimental analysis of ventral blood island hematopoiesis in Xenopus embryonic chimeras Dev Biol 131:302-312.

29. Rollins-Smith LA, Blair P. 1990. Contribution of ventral blood island mesoderm to hematopoiesis in postmetamorphic and metamorphosis-inhibited Xenopus laevis. Dev Biol 142:178-183.

30. Rollins-Smith LA, Parsons SCV, Cohen N. 1984. During frog ontogeny, PHA and Con A responsiveness of splenocytes precedes that of thymocytes. Immunology 52:491-500.

31. Kobel HR, Du Pasquier L. 1986. Genetics of polyploidy Xenopus. Trends Genet 2:310-315.

32. Graf J-D, Kobel HR. 1991. Genetics of Xenopus laevis. Methods Cell Biol 36:19-34.

33. Nieuwkoop PD, Faber J. 1967. Normal Table of Xenopus laevis (Daudin). North-Holland, Amsterdam, The Netherlands.

34. Kawahara H. 1978. Production of triploid and gynogenetic diploid Xenopus by cold treatment. Dev Growth Differ 20:227-236.

35. Katagiri C. 1961. On the fertilizability of the frog egg I. Journal of the Faculty of Science, Hokkaido University, Sapporo, Japan 14:607-613.

36. Bailey HC, Deanovic L, Reyes E, Kimball T, Larson K, Cortright K, Connor V, Hinton DE. 2000. Diazinon and chlorpyrifos in urban waterways in northern California, USA. Environ Toxicol Chem 19:82-87.

37. Handy RD, Abd-El Samei HA, Bayomy MFF, Mahran AM, Abdeen AM, El-Elaimy EA. 2002. Chronic diazinon exposure: Pathologies of spleen, thymus, blood cells, and lymph nodes are modulated by dietary protein or lipid in the mouse. Toxicology 172:13-34.

38. Barnett JB, Spyker-Cranmer JM, Avery DL, Hoberman AM. 1980. Immunocompetence over the lifespan of mice exposed in utero to carbofuran or diazinon: I. Changes in the serum immunoglobulin concentrations. J Environ Pathol Toxicol 4:53-63.

39. Faith RE, Luster MI, Kimmel CA. 1979. Effect of chronic developmental lead exposure on cell-mediated immune functions. Clin Exp Immunol 35:413-420.

40. Bunn TL, Marsh JA, Dietert RR. 2000. Gender differences in developmental immunotoxicity to lead in the chicken: Analysis following a single early low-level exposure in ovo. J Toxicol Environ Health Part A 61:677-693.

41. Bunn TL, Parsons PJ, Kao, Dietert RR. 2001. Exposure to lead during critical windows of embryonic development: Differential immunotoxic outcome based on stage of exposure and gender. Toxicol Sci 64:57-66.

42. Greulich K, Hoque E, Pflugmacher S. 2002. Uptake, metabolism, and effects on detoxication enzymes of isoproturon in spawn and tadpoles of amphibians. Ecotoxicol Environ Saf 52:256-266. 